\title{
Transient riboflavin depletion in preterm infants
}

\author{
A LUCAS AND C BATES \\ Medical Research Council, Dunn Nutrition Unit, Cambridge
}

SUMMARY Biochemical riboflavin status was measured in 68 preterm infants who were receiving either human milk or a preterm infant formula (containing riboflavin, $1.8 \mathrm{mg} / \mathrm{l}$ ) during the first few weeks of life. The relation between riboflavin status, type of diet, and time of introduction of a multivitamin supplement containing riboflavin was analysed and the duration of phototherapy was recorded. Those who received the multivitamin supplement on or before day 7 of life seldom became deficient and no significant difference between diets was seen in this group. Of those who received the supplement after day 7 , human milk fed infants commonly developed abnormal riboflavin status (18 out of 23 infants) compared with a small and significantly lower incidence in the formula fed group. Dietary effects on riboflavin status seemed to outweigh in importance those of phototherapy. It is concluded that the riboflavin content of human milk, which may be lowered by photodegradation, is not sufficient to ensure normal biochemical status in preterm infants. The larger amounts provided by a multivitamin supplement or by a preterm infant formula may, however, prevent biochemical deficiency. The desirability (and safety) of routine riboflavin supplementation of preterm infants is discussed.

Although a body of experimental evidence suggests that riboflavin plays a central role in intermediary metabolism and energy release, the requirement of preterm infants for this vitamin has received little scientific attention. Riboflavin, like most B vitamins, is not stored in appreciably greater amounts than are necessary to supply the enzymes for which it serves as a cofactor. Human milk contains lower concentrations than those seen in the milk of most other species. ${ }^{1-4}$ Riboflavin is also susceptible to photodegradation, so that destruction may occur during the processes of collection and treatment associated with the banking of human milk and the delivery of banked breast milk to the recipient.

Studies on riboflavin deficient rats have shown that the oxidation of fatty acids, in particular, is impaired by riboflavin deficiency. ${ }^{5-7}$ Such a lesion, if it were to occur in riboflavin deficient human infants, could have major implications for energy release during the early postnatal period where the utilisation of endogenous lipid fuels is of critical importance.

A study was carried out in two centres in East Anglia to determine whether preterm infants do indeed become deficient in riboflavin during the early postnatal period, whether the development of deficiency is related to the type of feed they receive, and whether it can be reversed by a multivitamin supplement.

\section{Subjects and methods}

Sixty eight preterm infants were studied at two intensive care units in the United Kingdom. This study formed part of a more extensive multicentre clinical trial on the biochemical, clinical, and developmental effects of several dietary regimens used currently for feeding low birthweight infants. In the first centre, where 52 infants were studied, it was the established policy to introduce a multivitamin supplement at the time when the babies attained full enteral feeding (180 to $200 \mathrm{ml} / \mathrm{kg} / 24$ hours), which was usually during the first two weeks of life. This supplement comprised an adult dose $(0.6 \mathrm{ml})$ of a proprietary mixture (Abidec: Parke Davis Ltd) containing vitamins $A, C$, and $D$; thiamine; riboflavin; vitamin $\mathrm{B}_{6}$; and nicotinamide and it provided $400 \mu \mathrm{g}$ riboflavin a day. In the second centre, where 16 babies were studied, the introduction of the vitamin supplement was delayed until the end of the second week, irrespective of the time when full enteral feeds were attained. Birthweight in the first

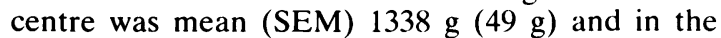

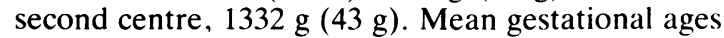


at birth in the two centres were $30 \cdot 4$ and $30 \cdot 6$ weeks respectively.

Sixty per cent of the babies received phototherapy for hyperbilirubinaemia during the first two weeks of life, the mean duration of treatment being 3.9 days.

At each centre infants whose mothers elected not to provide their own milk were randomly allocated to one of two diets: banked drip breast milk (collected from mothers locally) or a specially designed preterm infant formula of high caloric density, protein enriched, and providing $1.8 \mathrm{mg}$ riboflavin /l. If, on the other hand, mothers chose to supply their own milk, infants were randomly assigned to either banked drip breast milk or the preterm formula as a supplement to provide a total enteral feed intake of 180 to $200 \mathrm{ml} / \mathrm{kg} /$ day: in practice, however, the mean milk volume provided by mothers was small, so that the supplement comprised, on average, $70 \%$ of the dietary intake. Since no difference in riboflavin status was found between the group receiving the preterm formula as a sole diet and the group receiving it as a supplement to maternal milk, these two groups have been combined for analytical purposes and are referred to collectively, as the 'formula fed' group. For the same reason, infants receiving banked breast milk as a sole diet or as a supplement have been combined and are referred to as the 'human milk fed' group.

Venous blood samples, anticoagulated with heparin, were collected from each baby: usually twice during the first week of life and then once a week. They were centrifuged, the plasma and buffy coat were removed, and the packed red cells were stored at $-25^{\circ} \mathrm{C}$ for up to two months.

For analysis the samples were thawed, were diluted 1:1 with water, centrifuged to remove cell membranes, and the haemoglobin content adjusted to $0.75 \mathrm{~g} / \mathrm{l}$ with $0.1 \mathrm{M}$ potassium phosphate buffer,
pH $7 \cdot 4$ containing $3 \cdot 3 \times 10^{-3} \mathrm{M}$ EDTA. Part of this diluted haemolysate was incubated for 30 minutes at $37^{\circ} \mathrm{C}$ with flavin adenine dinucleotide, final concentration $2 \times 10^{-6} \mathrm{M}$, and part was incubated in parallel without added flavin adenine dinucleotide. Activity of erythrocyte $\mathrm{NAD}(\mathrm{P}) \mathrm{H}_{2}$ : glutathione oxidoreductase (EC 1.6.4.2: glutathione reductase) was then measured on a Roche Cobas Bioanalyser with oxidised glutathione at a final concentration of $6 \times 10^{-4} \mathrm{M}$ and $\mathrm{NADPH}_{2}$ at a final concentration of $1.32 \times 10^{-+} \mathrm{M}$. The ratio of the glutathione reductase activities in the presence and absence of flavin adenine dinucleotide (activation coefficient, EGRAC) is a well tested and widely accepted index of riboflavin status. ${ }^{x-11} \mathrm{~A}$ raised value of the activation coefficient EGRAC is evidence of suboptimal riboflavin supply to the tissues. For the purpose of the present study it was considered appropriate to accept an EGRAC value of 1.3 as the upper limit of normality, as has been done previously,,$^{12} 1.3$ although the assay procedure has now been slightly modified, to make it more sensitive to marginal deficiency conditions.

\section{Results}

The Table presents the results of analysis of peab EGRAC values for each infant, both in terms of

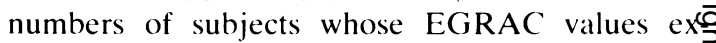
ceeded 1.3 and of the actual peak values recorded: Both approaches indicate that, of the babies studied in centre 1 , those who received the multivitamin supplement before or on day 7 showed no significant evidence of a diet related difference in incidence of raised (that is deficient) EGRAC values, whereas those who received the supplement after day 7 showed a significant diet related difference-the human milk fed group having a higher incidence of deficiency and higher mean peak values than the

Table Comparison between human milk and infant formula feeds on the incidence and peak values of raised EC $; R A C$

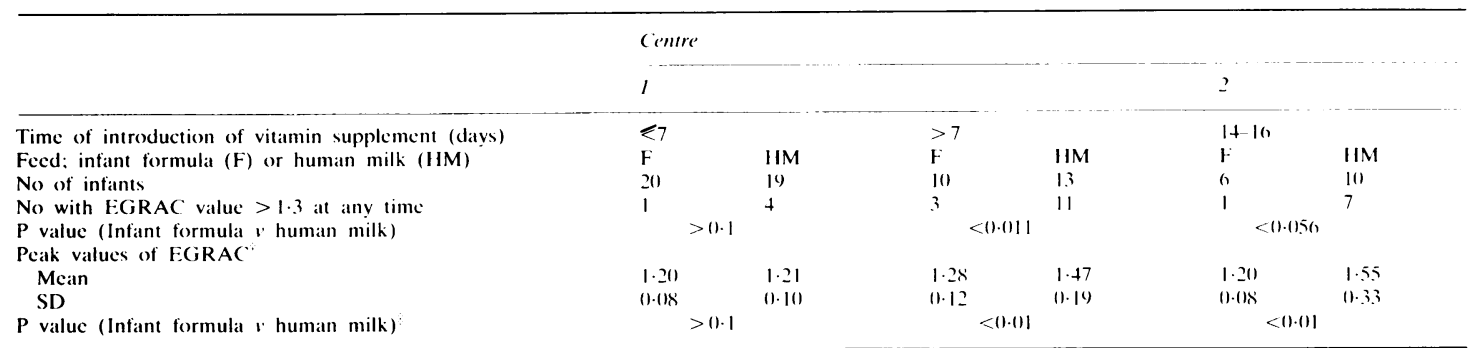

Comparison between groups by Fisher's exact probability test.

Maximum values for each subject, irrespective of when the occurred.

Comparison between groups by Student's $t$ test.

EGRAC = glutathione reductase activity with added flavin adenine dinucleotide/glutathione reductase activity without added flavin adenine dinucleotide 
formula fed group. In centre 2, where the multivitamin supplement was routinely introduced between day 14 and day 16 , there was again a significantly greater incidence of raised values and a higher mean peak value in the human milk fed group than in the formula fed group.

The Figure shows the results in terms of mean EGRAC values for infants of different age ranges in the three groups: infants studied in centre 1 supplemented before or on day 7 : infants in centre 1 supplemented after day 7; and infants in centre 2 . Again it is evident that raised values occurred predominantly in the group fed human milk, and within that group, in infants who received the vitamin supplement relatively late. Values as high as

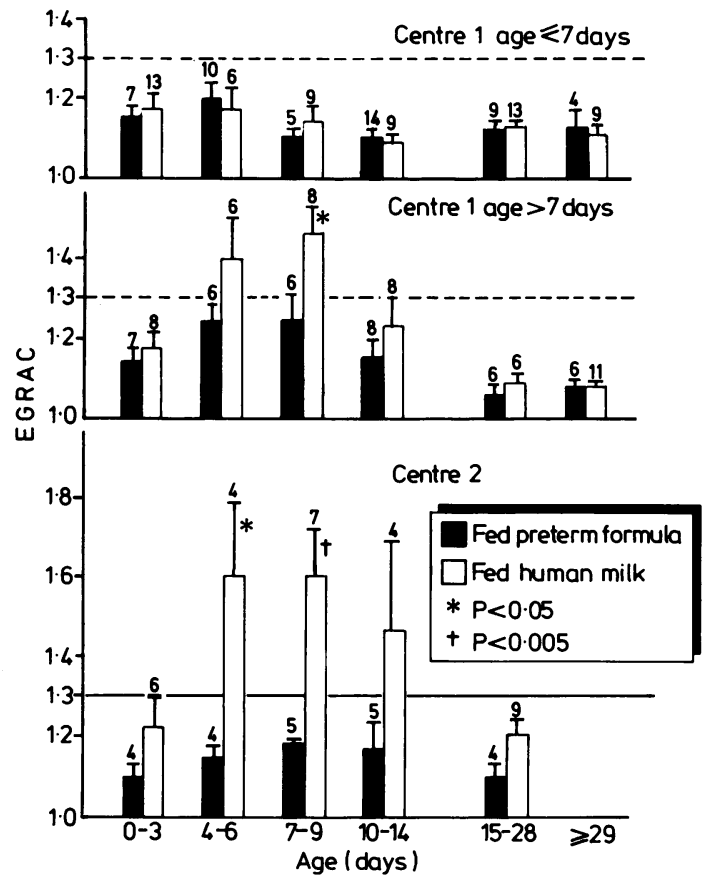

Figure Comparison between centres and effect of infants' age and time of introduction of vitamin supplement on EGRAC * (mean $+S E$ with number of observations given above).

Data obtained at centre 1 , where the infants received vitamin supplement at the time when they attained full enteral feeding, are subdivided into two groups: those from infants who were supplemented on or before the seventh day of life, and those from infants supplemented after the seventh day. At centre 2, all the infants were supplemented at the end of the second week of life (days 14 to 16) irrespective of the time of attainment of full enteral feeds. Several measurements were made on each subject during the study, but no subject is represented more than once in a particular age group.

${ }^{*}$ EGRAC $=$ glutathione reductase activity with added flavin adenine dinucleotide/glutathione reductase activity without added flavin adenine dinucleotide.

The line at EGRAC $=1.3$ represents the upper limit of biochemical normality.
$2 \cdot 0$ were observed in two infants at centre 2 , just before the introduction of the supplement, but these returned to normal rapidly once the supplement had been introduced.

In centre 2 it was clear that relatively late introduction of the vitamin supplement was more important than phototherapy in determining riboflavin status. Of six infants receiving human milk and no phototherapy, five developed deficient riboflavin status, and of four receiving human milk with phototherapy, three developed deficiency. In centre 1 , the relation was more complex because the infants who received phototherapy also tended to be those who received the multivitamin supplement latest, because they were more likely to be ill and, therefore, to reach full feeds comparatively late. Regression analysis, however, showed that the relation between EGRAC and phototherapy in centre 1 did not reach significance at the 5\% probability level, nor did it interfere with the significance of the relation between EGRAC and diet, or between EGRAC and age when multivitamin supplementation was begun.

\section{Discussion}

The two factors which were clearly associated with biochemical evidence of impaired riboflavin status in term infants in this study were the relatively late introduction of multivitamin supplement and the use of human milk instead of riboflavin supplemented infant formula as the primary diet. Five infants who developed significantly raised values of EGRAC despite being allocated to the formula diet group had received only small amounts of the diet (2-32 $\mathrm{ml} / \mathrm{kg} /$ day) up to the time when the peak occurred.

Two factors complicated the interpretation of the study at centre 1 . Firstly, babies who received the multivitamin supplement late were also those who were ill and could not, therefore, tolerate full enteral feeding at an early stage. The fact that higher EGRAC values were encountered in infants at centre 2 than at centre 1 , despite the fact that the delay in the introduction of the vitamin supplement in centre 2 was a routine policy unrelated to the infants' state of health, indicates, however, that the vitamin supplement rather than health status was the critical factor. Indeed, well infants who were receiving full enteral feeds were at high risk if the feed consisted of human milk alone.

The second complicating factor was that babies who received the vitamin supplement late were in many cases those who received the longest periods of phototherapy for hyperbilirubinaemia. Several recent studies have recorded a deterioration biochemical riboflavin status as a result of photo- 
therapy, both in term ${ }^{1+16}$ and preterm infants. ${ }^{14}$ The present study was not designed specifically to test the effect of phototherapy and firm conclusions about it cannot be drawn. It is clear, however, that diet and time of introduction of supplement together outweighed any effect of phototherapy and were the dominating influences.

For those infants who received the multivitamin supplement before the seventh day of life, it made little difference to their status whether they received formula feed or human milk. But for those who first received it after this time, and especially for those who received it as late as day 14 , the choice of diet was critical.

A recent study of the composition of mature human milk from mothers in the United Kingdom ${ }^{17}$ has recorded a mean riboflavin concentration of 310 $\mu \mathrm{g} / \mathrm{l}(0.82 \mu \mathrm{mol} / \mathrm{l})$ from 96 mothers in five towns. The amount present in the preterm formula was six times as high $-1.8 \mathrm{mg} / \mathrm{l}$. Thus, a baby receiving full enteral feeds would obtain $324 \mu \mathrm{g}$ riboflavin from the formula (at $180 \mathrm{mg} / \mathrm{kg} / \mathrm{day}$ ), but only $60 \mu \mathrm{g}$ from breast milk (at $200 \mathrm{ml} / \mathrm{kg} / \mathrm{day}$ ), assuming no loss during feed administration. Our preliminary observations show, however, that substantial and variable loss of riboflavin may occur during exposure of breast milk or of infant formula to light, in the course of its delivery.

Little is known about requirements of very young babies and preterm infants. Hovi et al $^{15}$ found that term infants who received breast milk as their sole source of riboflavin developed abnormal riboflavin status during the first two weeks of life, even if no phototherapy was given. The present study extends this conclusion to preterm infants. Meloni et al ${ }^{18}$ found abnormal riboflavin status in term babies fed an infant formula containing $1.12 \mathrm{mg}$ riboflavin/l, although the relation between status and intake was not quantitatively measured. Clearly, further studies of this relation are needed, both for term and preterm infants. Since riboflavin deficiency is both more common and more severe in third world than in western countries ${ }^{12}{ }^{1.3}$ it is important to assess its impact in several communities.

The metabolic implications of moderate impairment of riboflavin status require investigation by controlled feeding trial, to determine whether fatty acid oxidation or other riboflavin dependent systems are impaired appreciably as a result of the transient deficiency observed in preterm infants. Low circulating ketone values were, in fact, observed in the infants with EGRAC above 1.3 in the present study, but a causal relation has not yet been established.

In conclusion, our data provide evidence that intakes of riboflavin beginning before the seventh postnatal day may need to be greater than 60 $\mu \mathrm{g} / \mathrm{kg} /$ day (provided by unsupplemented human $\stackrel{\rho}{工}$ milk) but that a dose of around $300 \mu \mathrm{g}$ riboflavin $/ \mathrm{kg} / \frac{\mathrm{Q}}{\mathrm{O}}$ day, provided by the infant formula without addi- $\vec{F}$ tional vitamin supplement (or somewhat less, since $\stackrel{\rho}{?}$ some of the formula fed group received a proportion $\bar{c}$ of their diet as maternal milk) is sufficient to maintain 'normal' riboflavin status. In view of the $\frac{\rho}{7}$ photosensitising nature of riboflavin and its conse- $\stackrel{\mathbb{Q}}{\complement}$ quent ability to enhance light induced damage to genetic material, ${ }^{19}$ it might be unwise to administer $\vec{\circ}$ large doses of riboflavin to infants until phototherapy has been stopped. Infants requiring a period of $\overrightarrow{\vec{\omega}}$ phototherapy extending well into the second post- o natal week thus pose an unsolved problem-the relative risks of phototherapy in riboflavin supplemented infants and those of riboflavin deficiency due to lack of supplementation need to be explored by future clinical studies.

We thank Mrs Karen Tumber and Miss Gail Goldberg for assistance with the EGRAC assays. the staff of the special care $\Theta$ baby units at Mill Road Maternity Hospital. Cambridge. and Heath $\frac{\mathbb{D}}{O}$ Road Hospital. Ipswich, for their help and cooperation, and Farley $\mathbb{D}$ Health Products for their technical and financial contribution to the feeding studies carried out at these centres.

\section{References}

György P. Quantitative estimation of lactoflavin and of vitamm $B_{6}$ in cow's milk and in human milk. Proc Soc Exp Biol Me 1936:35:204-7.

2 Neuwiler W. Über den Flavingehalt der Frauenmilch. Klin Wochenschr 1973:16:1348-50.

Grichel C. Enthält dic Fraucnmilch Laktoflavin (Vitamin $\mathrm{B}_{2}$ )? Ernärhung 1937:2:68-70.

+ Kon SK, Mawson EH. Human milk. Wartime studies of certain vitamins and other constituents. Medical Research Council Special Report Series no. 269. 1950:1(04-20.

Hoppel C. Di Marco JP. Tandler B. Riboflavin and rat hepatic cell structure and function. J Biol Chem 1979:254:4164-70.

"Sakurai T. Miyazawa S. Furuta S. Hashimoto T. Riboflavin deficiency and B-oxidation systems in rat liver. Lipids 1982:17:598-604.

Olpin SE. Bates CJ. Lipid metabolism in riboflavin-deficien rats. 1. Effect of dietary lipids on riboflavin status and fatty acid profiles. $\mathrm{Br} J$ Nutr 1982:47:577-82.

Bamji MS. Glutathione reductase activity in red blood cells and riboflavin nutritional status in humans. Clin Chim Acta 1969:26:26.3-9.

"Beutler E. Effect of flavin compounds on glutathione reductase activity in vivo and in vitro studies. J Clin Invest 1969:48: 1957-66.

"I Glatzle D. Körner WF. Christeller S. Wiss O. Method for the detection of a biochemical riboflavin deficiency. Stimulation of $G$ NADPH $H_{2}$-dependent glutathione reductase from human $\mathrm{N}$ erythrocytes hy FAD in vitro. Investigations on vitamin $\mathrm{B}_{2}$ status in healthy people and geriatric patients. Int J Vitam Nutr Res $\omega$ 1970;40: 166-83.

1 Tilotson JA. Baker EM. An enzymatic measurement of the riboflavin status in man. Am J Clin Nutr 1972;25:425-31.

12 Bates CJ. Prentice AM, Paul AA. Prentice A, Sutcliffe BA. Whitchead RG. Riboflavin status in infants born in rural Gambia, and the effect of a weaning food supplement. Trans $R$ Soc Trop Med Hyg 1982:76:253-8. 
${ }^{13}$ Bates CJ, Prentice AM, Watkinson M. et al. Riboflavin requirements of lactating Gambian women: a controlled supplementation trial. Am J Clin Nutr 1982:35:701-9.

it Gromisch DS. Lopez R. Cole HS. Cooperman JM. Light (phototherapy)-induced riboflavin deficiency in the nconate. J Pediatr 1977:90:118-22.

15 Hovi L, Hekali R, Siimes MA. Evidence of riboflavin depletion in breast-fed newborns and its further acceleration during treatment of hyperbilirubinaemia by phototherapy. Acta Paediatr Scand 1979;68:567-70.

16 Tan KL, Chow MT, Karim SMM. Effect of phototherapy on nconatal riboflavin status. J Pediatr 1978:93:494-7.

${ }^{17}$ Department of Health and Social Security. Report on Health and Social Subjects 12. The composition of mature human milk.
(Report of a Working Party of the Committec on Medical Aspects of Food Policy.) London: HMSO. 1977.

is Meloni T, Corti R, Naitana AF. Arese P. Lack of effect of phototherapy on red cell riboflavin status and on glucose 6-phosphate dehydrogenase activity in normal and G-6-PDdeficient subjects with neonatal jaundice. $J$ Pediatr 1982:100:972-4.

1" Speck WT, Chen CC. Rosenkranz HS. In vitro studies of effects of light and riboflavin on DNA and HeLa cells. Pediatr Res 1975:9:150-3.

Correspondence to Dr A Lucas. MRC Dunn Nutrition Laboratory. Milton Road. Cambridge CB4 IXJ.

Received 30 May 1984 